\title{
Learning actions, objects and types of interaction: A methodological analysis of expansive learning among pre-service teachers
}

\author{
Juhana Rantavuori ${ }^{1}$, Yrjö Engeström, Lasse Lipponen \\ University of Helsinki, Finland \\ Article received 8 May / revised 24 March / accepted 6 April / available online 10 May
}

\begin{abstract}
The paper analyzes a collaborative learning process among Finnish pre-service teachers planning their own learning in a self-regulated way. The study builds on culturalhistorical activity theory and the theory of expansive learning, integrating for the first time an analysis of learning actions and an analysis of types of interaction. We examine the theory of expansive learning as a possible conceptual and methodological framework for understanding this type of collaborative learning. The task of the paper is primarily methodological. We believe that cultural-historical activity theory needs to be turned into methods and procedures of systematic empirical analysis, and this article examines one such methodological solution. At the same time, we aim to uncover some substantive dynamics of expansive learning in collaborative teacher education oriented at openended problems and tasks. An almost complete expansive mini-cycle of learning actions appeared in the pre-service teachers' meeting. However, an analysis of the steps of formation of the shared object revealed a more complex iterative process. As the expansive learning process moved epistemically from questioning to analysis, modeling and implementation, it also moved interactionally from coordination to cooperation and communication. Yet there was no mechanical correspondence between specific learning actions and specific types of interaction. Transitions and disturbances were crucial for the dynamics of expansive learning. A full assessment of a potentially expansive minicycle of learning calls for extending the time scale of the analysis.
\end{abstract}

Keywords: Activity theory; expansive learning; learning actions; types of interaction; object; disturbances

\footnotetext{
${ }^{1}$ Corresponding author: Juhana Rantavuori, Center for Research on Activity, Development, and Learning, Institute of Behavioural Sciences, Faculty of Behavioural Sciences, PO Box 9 (Siltavuorenpenger 1A), FI-00014 University of Helsinki, Finland. E-mail: juhana.rantavuori@helsinki.fi. DOI: http://dx.doi.org/10.14786/flr.v4i3.174
} 


\section{Introduction}

Open-ended and problem-based collaborative learning is becoming an increasingly important challenge for many contexts in which learners face complex problems for which pre-existing standard solutions are not sufficient (Bereiter \& Scardamalia, 1993). We argue that it is not enough to promote collaborative and problem-oriented learning in general. Theoretically ambitious models and empirically rigorous methods are needed for the design and assessment of such learning processes (see Goldman, 2014). In this paper, we will analyze a collaborative learning process among Finnish pre-service teachers. In this particular process, the pre-service teachers were responsible for planning their own learning actions and goals. We examine the theory of expansive learning (Engeström, 2015) as a possible conceptual and methodological framework for understanding this type of learning.

More generally, our study contributes to research on learning and interaction in activity systems, especially to how learning and interaction are connected in open-ended problem solving. Activity systems are systems where people engage in solving problems or making or designing something (Greeno, 2011; Greeno \& Engeström, 2014). They are "dynamic, open, semiotic system(s) of meaningful actions and meaning-making processes" (Lemke, 1990, p. 191). An activity system can be as small as an individual working with a computer, or as large as an organization having hundreds of employees. In our case, the activity system is a group of pre-service teachers, working on an open-ended problem solving task in a selfregulated way.

The task of the paper is primarily methodological. We believe that cultural-historical activity theory needs to be turned into methods and procedures of systematic empirical analysis. Therefore, the aim of the paper is to contribute to the construction of a methodology for analyzing dynamics of expansive learning. A new methodological framework created in this study is tested in the analysis of a planning meeting of a preservice teacher group.

Our study is focused on two important aspects of expansive learning, namely types and sequences of expansive learning actions (Engeström \& Sannino, 2010) and types and sequences of object-oriented interaction (Engeström, 2008; Fichtner, 1984; Raiethel, 1983). Our aim is to understand what kinds of learning actions pre-service teachers conduct and in what types of interaction they engage in a collaborative learning process characterized by self-regulation and open-ended problem-solving. Expansive learning actions have been studied in detail previously (e.g., Engeström, Rantavuori, \& Kerosuo, 2013; Foot, 2001; Nilsson, 2003; Seppänen, 2004), and so have types of object-oriented interaction (e.g., de Lange, 2011; Saari; 1995). However, no studies have thus far combined learning actions and types of interaction into an integrated analysis. To fully understand the nature of open-ended and problem-based collaborative learning, and to develop the methodology of expansive learning, we need to combine these two analyses. No studies have done this up until the present.

Studies of expansive learning have often been based on interventions, such as Change Laboratories (Virkkunen \& Newnham, 2013), deliberately designed to implement expansive learning (e.g., Engeström et al., 2013). This was not the case in the process we analyze in this paper. In this sense, our case resembles an earlier study of innovative learning in industrial work teams (Engeström, 2008, pp. 118-168). The assumption of these studies is that features of expansive learning may be found in processes in which the learners face a problem or task that needs to be defined by the learners themselves and has no predefined procedure to follow or correct solution to aim at. Furthermore, these studies see an inherent tension and conflict of motives in these learning processes between the safe and easy but probably rather unproductive option of following the available routine script in dealing with the task on the one hand, and the risky and difficult but possibly very productive option of turning the task into a new, expanded object and way of working on the other hand. Our study examines a single learning session. Full-fledged cycles of expansive learning consist of mini-cycles which may be detected and fostered within single learning sessions or other 


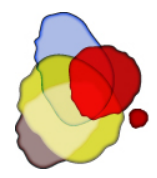

compact sequences of learning efforts. Thus, from the point of view of the theory of expansive learning, our study addresses three interrelated methodological challenges: (a) combining and integrating for the first time an analysis of learning actions and an analysis of types of interaction, (b) examining possible features of expansive learning in a process which was not designed to accomplish expansive learning by deliberate intervention, and (c) examining possible evidence for a mini-cycle of expansive learning within a single learning session. In other words, the task of this article is to explore and elaborate on the explanatory potential of the theory of expansive learning in a context of learning to which it has not been usually applied, and to develop methodological tools for examining the potential of the theory in a systematic manner. Added to this, the task of the article is also to show which role the mutual interaction between the participants plays in the expansive learning process.

In what follows, we will first present the theoretical framework, the methodology used in the study, and the research questions. After that we describe the context of the study and the data collected. We then analyze our data in four sections, each devoted to one of our four research questions. Finally, we discuss our findings and consider their methodological implications for the framework of expansive learning and for research on learning more generally.

\section{Theoretical framework}

\subsection{Theory of expansive learning}

Sfard (1998) suggested that there are two basic metaphors of learning competing for dominance: the acquisition metaphor and the participation metaphor. The key dimension underlying Sfard's dichotomy is derived from the question: Is the learner to be understood primarily as an individual or as a community? This is an important dimension, largely inspired by the notion of community of practice put forward by Lave and Wenger (1991) and Wenger (1998). However, an attempt to construct a one-dimensional conceptual space for the identification, analysis and comparison of theories is bound to eliminate too much of the complexity of the field of learning.

The theory of expansive learning puts the primacy on communities as learners, on transformation and creation of culture, on horizontal movement and hybridization, and on the formation of theoretical concepts. In fact, from the point of view of expansive learning, both acquisition-based and participationbased approaches share much of the same conservative bias. Both have little to say about transformation and creation of culture. Both acquisition-based and participation-based approaches, depict learning primarily as one-way movement from incompetence to competence, with little serious analysis devoted to horizontal movement and hybridization. Acquisition-based approaches may ostensibly value theoretical concepts, but their very theory of concepts is quite uniformly empiricist and formal (Davydov, 1990). Participation-based approaches are commonly suspicious if not hostile toward the formation of theoretical concepts, largely because these approaches, too, see theoretical concepts mainly as formal 'bookish' abstractions.

So the theory of expansive learning must rely on its own metaphor: expansion. The core idea is qualitatively different from both acquisition and participation. In expansive learning, learners learn something that is not yet there. In other words, the learners construct a new object and concept for their collective activity, and implement this new object and concept in practice.

Traditional modes of learning deal with tasks in which the contents to be learned are well known ahead of time by those who design, manage, and implement various programs of learning. When whole collective activity systems, such as work processes and organizations, need to redefine themselves, traditional modes of learning are not enough. Nobody knows exactly what needs to be learned. The design of 
the new activity and the acquisition of the knowledge and skills it requires are increasingly intertwined. In expansive learning activity, they merge.

Relying on activity theory, the theory of expansive learning is foundationally an object-oriented theory. In other words, the object is both resistant raw material and the future-oriented purpose of an activity. The object is the true carrier of the motive of the activity. Thus, in expansive learning activity, motives and motivation are not sought primarily inside individual subjects - they are in the object to be transformed and expanded.

In educational settings, the students' object is a contradictory unity of meaningful knowledge (use value) and grades (exchange value). A powerful object of learning has expansive potential to go beyond the exchange value, being typically an open-ended problem or challenge that has relevance for the learners not limited to reproducing predefined correct answers. Such an object of learning typically also goes beyond verbal formulations, requiring transformative material actions of experimentation, modeling, and implementation in practice.

The theory of expansive learning is based on the dialectics of ascending from the abstract to the concrete (Engeström \& Sannino, 2010). This is a method of grasping the essence of an object by tracing and theoretically reproducing the logic of its development, that is, its historical formation through the emergence and resolution of its inner contradictions. A new theoretical idea or concept is initially produced in the form of an abstract, simple explanatory relationship, a germ cell. This initial abstraction is enriched and transformed step-by-step into a concrete system of multiple, constantly developing manifestations. In an expansive learning cycle, the initial simple idea is transformed into a complex object, a new form of practice. A successful expansive cycle produces a new theoretical concept - theoretically grasped practice - concrete in its systemic richness and multiplicity of manifestations. The expansive cycle begins with individual subjects questioning the accepted practice, and it gradually expands into a collective effort.

In educational contexts, the most well-known example of ascending from the abstract to the concrete is Davydov's (1990) work on elementary school mathematics learning. For Davydov, the germ cell of mathematics is real number, which is a particular case of a general relationship of quantities, where one of them is taken as a measure for computing the other. A number is obtained by the general formula $A / C=N$, in which $\mathrm{N}$ is any number, $\mathrm{A}$ is any object represented as a quantity, and $\mathrm{C}$ is any measure (Davydov, 1990, pp. 361-362). From working out and operating with this foundational relationship, or abstract germ cell, Davydov built a whole curriculum that resulted in a mastery of a rich and concrete diversity of mathematical phenomena and tasks (Schmittau \& Morris, 2004). In subsequent studies of expansive learning, the learning challenge has often been more problematic, stemming from contradictions that need to be resolved. In these studies, the germ cell is initially not known by the instructor-interventionists themselves; it has to be discovered and modeled by the participants investigating and transforming their activity and knowledge domain (Engeström \& Sannino, 2010).

Expansive learning may be described as a stepwise process that involves seven phases called learning actions. Together these actions form an expansive cycle. This sequential model should be understood as an idealized tool for analyzing elements of expansive learning; real cycles of expansive learning do not neatly follow the order depicted in the theoretical model. Process theories of learning are unavoidable to some extent prescriptive in that they advocate some optimal or desirable model of the learning process. This carries the risk of self-fulfilling prophecy, that is, as design-oriented researcher may impose his or her theoretical model on learners and instructors and seek confirmation for the model from evidence stemming from such pre-designed practice. There are good ways to keep this tendency in check (Engeström \& Sannino, 2012). In the present study, the learning process was not designed to follow the theoretical model of expansive learning to begin with.

An ideal-typical sequence of learning actions in an expansive cycle can be described as follows (Engeström \& Sannino, 2010, p. 7). 
- The first action of an expansive cycle is that of questioning, criticizing, or rejecting some aspects of accepted practice and existing wisdom.

- The second action is that of analyzing the situation. Analysis involves mental, discursive, or practical transformation of the situation in order to discover causes or explanatory mechanisms. Analysis evokes "why" questions and explanatory principles. One type of analysis is historicalgenetic; it seeks to explain the situation by tracing its origination and evolution. Another type of analysis is actual-empirical; it seeks to explain the situation by constructing a picture of its inner systemic relations.

- The third action is that of modeling the newly found explanatory relationship in some publicly observable and transmittable form. This means constructing an explicit, simplified model of the new idea that explains and offers a solution to the problematic situation.

- The fourth action is that of examining the model, running, operating, and experimenting on it in order to fully grasp its dynamics, potentials, and limitations.

- The fifth action is that of implementing the model, concretizing it by means of practical applications, enrichments, and conceptual extensions.

- The sixth and seventh actions are those of reflecting on and evaluating the process and consolidating its outcomes into a new, stable form of practice.

The model of expansive learning is useful when we try to understand open-ended learning processes in which the problem and its solution are not predefined, and the participants must learn something that "is not yet there", that is, to generate and appropriate culturally new practices and knowledge. Expansive learning has mostly been studied in relatively long-term transformations and interventions. However, "largescale cycles involve numerous smaller cycles of learning actions" (Engeström \& Sannino, 2010). Such a mini-cycle may take place within a single intensive meeting of a group charged with a task of analyzing and solving a problem important for the development of its overall activity (e.g., Engeström, 2008).

Although the theory of expansive learning proposes that full-fledged sequences of expansive learning actions typically take the shape of relatively predictable cycles, the cycle of expansive learning is not a universal formula of phases or stages. In fact, one probably never finds a concrete collective learning process which purely follows the ideal-typical model. The model is a heuristic conceptual tool derived from the logic of ascending from the abstract to the concrete. Every time one examines or facilitates a potentially expansive learning process with the help of the model, one tests, criticizes and hopefully enriches the theoretical ideas of the model.

Learning processes are never purely expansive. They contain both expansive and non-expansive phases, steps forward and back, and digressions from expanding the object of activity (Engeström et al., 2013). In the study of innovative learning in industrial work teams (Engeström, 2008, pp. 118-168), two such non-expansive actions were identified, namely formulating/debating a problem and reinforcing existing practice. A Change Laboratory process in a Finnish library (Engeström et al., 2013) revealed three nonexpansive actions, namely informing, clarifying, and summarizing. In this study we followed the criteria of these previous studies for identifying the non-expansive learning actions. In expansive learning the emergence of a new expanding object is decisive. If such a new object was not found, the learning action was identified as non-expansive. These actions were then named descriptively, on the basis of their contents, without aiming at a theoretically systematic categorization. However, these non-expansive actions are not inimical or opposite to expansive learning, but unnecessary elements of the epistemic process of ascending from the abstract to the concrete.

\section{$2.2 \quad$ Object-oriented interaction}

The learning actions of the expansive cycle do not dictate what kinds of social interaction are involved in the learning process. To capture this aspect, we used the framework of three types of objectoriented interaction, namely coordination, cooperation, and communication. These three types of interaction 
can be understood as qualitatively different types of epistemological subject-object-subject relations (Raiethel, 1983; Fichtner, 1984; Engeström, 2008).

One basic idea to define collaboration is to make a distinction between cooperation and collaboration. According to Dillenbourg, Baker, Blaye, and O'Malley (1996), cooperation is accomplished by the division of labor among the participants; each person is responsible for a portion of the problemsolving task. By contrast, collaboration is "a coordinated, synchronous activity that is the result of a continued attempt to construct and maintain a shared conception of a problem" (Roschelle \& Teasley, 1995, p. 70). In this article cooperation and collaboration are used as specific concepts which are part of the analytical framework of three qualitative types of interaction. Therefore, our intention is not to participate in the larger ongoing discussion concerning the use concepts of cooperation and collaboration in educational research.

Coordination is the "default" mode of interaction in groups, experienced as business-as-usual. In coordination, each participant focuses on and performs his or her own scripted role and tasks. The script, coded in written rules, plans, and agendas or engraved in tacitly assumed traditions, coordinates the participants' actions as if from behind their backs, without being questioned or discussed. Each participant has his or her own partial object or task; the possible shared object is not articulated and participants engage in dialogue mainly to maintain and adjust boundaries between their respective tasks and roles.

Cooperation is typically initiated when the participants face a discoordination, that is, a disturbance or problem that cannot be fixed simply by returning to the prescribed script. In cooperative interactions, participants focus on a shared problem, trying to find mutually acceptable ways to understand, conceptualize, and work on it. In this mode, the given script is temporarily suspended and actions are driven by the demands of the shared object. Participants address each other dialogically and there is typically a marked increase in the intensity of the discourse, often manifested in overlapping talk and similar indications of increased engagement. Cooperation may remain a mere attempt, typically when a participant initiates it but receives no or only minimal responses from the interlocutors. Such an attempt often stands out as a disturbance in that it deviates from the standard script of the interaction.

Interaction may also take the shape of pseudo-cooperation. In this case, participants interact in a way that resembles cooperation; they address and respond to one another, often talking about something that is perceived as problematic. However, pseudo-cooperation focuses on a substitute object, often an "eternal issue" that can be discussed ad infinitum without ever approaching a resolution. Pseudo-cooperation commonly resembles collective venting, sometimes also grumbling or complaining.

Communication is usually initiated when the participants experience recurring conflicts or breakdowns in their coordination and cooperation. In communication, the participants question and examine their own patterns of interaction in relation to their shared object. As a result, both the object and the script are reconceptualized. This type of self-reflective and transformative phases in interaction are rare and difficult to sustain without the mobilization of novel resources, such as shared documentation, plans, or outside help.

Overall, the framework of expansive learning calls attention to transitions between types of interaction. As the transitions are typically triggered by discoordinations, conflicts, ruptures and breakdowns, the analysis of types of interaction needs to pay special attention to these kinds of disturbances. Often when coordination is interrupted or breaks down, it turns into a cooperation attempt or communication attempt which may or may not lead to a phase of full-fledged cooperation or communication. Fluid, pulsating movement from coordination to cooperation and communication and back should be a hallmark of expansive learning characterized by a longitudinal effort to redefine the object of the collective activity. 


\subsection{Object formation}

Expansive learning is a process of identifying, articulating, reconceptualizing and expanding the object of the activity. In her activity-theoretical study of an elementary school teacher team planning and implementing an innovative curriculum unit, Kärkkäinen (1999) identified three phases in the formation of the object of planning. Shifts from one phase to the next one were described as turning points, characterized by clusters of disturbances and questioning. A simplified ideal-typical sequence of the formation of the object in expansive learning may be depicted with the help of Figure 1.

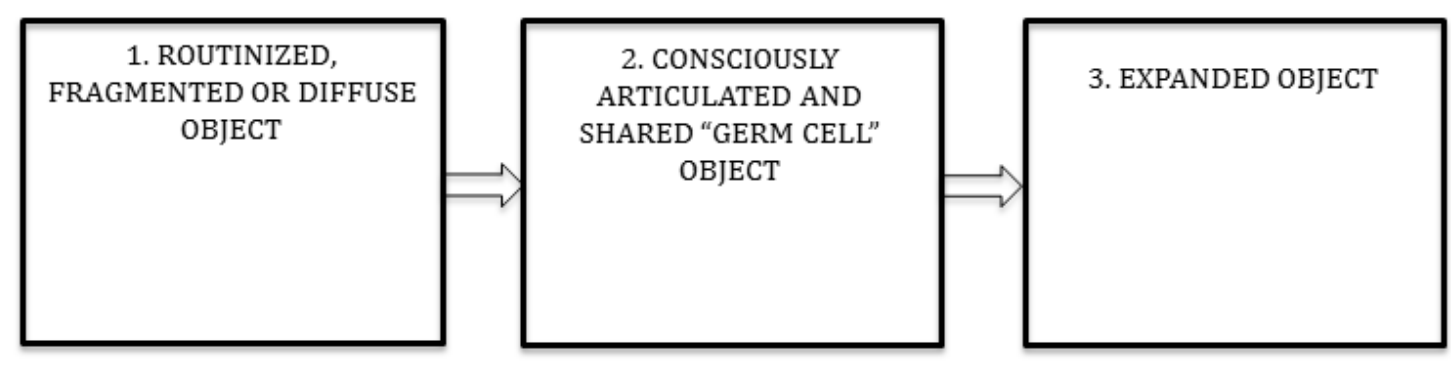

Figure 1. Ideal-typical phases of the formation of the object in expansive learning.

In the first phase depicted in Figure 1, the object of the activity may be in crisis due to fragmentation and routinization that prevent the practitioners from facing and embracing new challenges and opportunities in their activity. Alternatively, the object may be in such an embryonic state of emergence that it is only vaguely and diffusely grasped and understood by the participants. In the second phase of Figure 1, the participants articulate, conceptualize and model a new object for their activity. This new object is typically still a relatively abstract initial idea or principle, a "germ cell", the expansive implications and potentials of which are not yet realized. In the third phase, the new object is expanded and made concrete, in other words, its manifold practical consequences, extensions, and applications are integrated into a complex totality.

\section{Research questions}

To analyze and understand the pre-service teachers' collaborative learning process, we pose the questions enumerated in Table 1. Our research questions are driven by our methodological interest in examining the analytical potential of the framework of expansive learning with data from a learning context which was not deliberately designed to follow the guidelines of expansive learning. Thus, the methodological questions in Table 1 are of primary importance. The substantive questions may be read as tools with which the methodological questions are approached and made concrete. 
Table 1

\section{Research questions}

Methodological research questions

1. How does the conceptual framework of expansive learning actions work in the analysis of data from a single session of collaborative learning not deliberately designed to follow the guidelines of expansive learning?

2. How does the conceptual framework of the object formation work in the analysis of data from a single session of collaborative learning not deliberately designed to follow the guidelines of expansive learning?

3. How does the conceptual framework of types of object-oriented interaction work in the analysis of data from a single session of collaborative learning not deliberately designed to follow the guidelines of expansive learning?

4. How does the integration of conceptual frameworks of expansive learning actions and types of interaction work in the analysis of data from a single session of collaborative learning not deliberately designed to follow the guidelines of expansive learning?
Auxiliary substantive questions

1. Which expansive learning actions can be identified in the learning process of the pre-service teacher group?

2. How was the shared object formed in the learning process of the pre-service teacher group?

3. How were the types of interaction and transitions between them manifested during the collaborative learning process?

4. What was the relationship between expansive learning actions and types of interaction?

\section{Participants and Context of the Study}

The participants in the study were six pre-service teachers. They were enrolled in a class teacher education program (primary school level) with annual intake of ten students, with educational psychology as their major. The nearest equivalent to a term class teacher outside of Finland is a primary school teacher (UK) or an elementary school teacher (USA). At the time of the data collection, the students were in their fourth year.

In class teacher education at University of Helsinki, students complete a Master of Arts (Education), the completion of which takes approximately five years. The class teacher education at the University of Helsinki consists of two different study programs. The major subject may be either education or educational psychology. The core contents of the major subject studies in educational psychology include working as a member of a group and interaction skills; learning, growth, and development; curriculum work and learning to deal with the reality of school life; as well as learning to conduct research. The students in this program study intensively as a small group approximately for three years, applying self-regulated, collaborative learning as one of their main approaches (see Eteläpelto, Littleton, Lahti, \& Wirtanen, 2005; Lipponen \& Kumpulainen, 2011). The pre-service teachers who participated in this study were thus already socialized into working and interacting within a pedagogical culture that built on collective discussion and collaboration on open-ended and largely self-designed tasks. Their activity was that of a new type of university study characterized by self-directed collaborative planning and implementation. However, this new activity existed side by side with the traditional type of university study, characterized by individual 


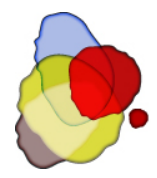

work on assignments given from above. A tension between these two scripts is an inherent feature of the activity analyzed here.

In this article, we analyze a meeting of the pre-service teachers' group at the beginning of a threemonth course. This course was part of the large study module called "Multidisciplinary studies of school subjects taught in the comprehensive school". During this study module students studied all 13 subjects which are taught in the primary school (grades 1-6). Usually each subject is taught in its own separate course by the subject expert (teacher educator). In the teacher education program analyzed in this paper the entire study module was arranged in multidisciplinary way. In the beginning of the module the student group chose three multidisciplinary themes, that were "Sustainable development", "Human being" and "Time". The selection of themes was a process were student group together created a joint conception of the important phenomena of the world. Therefore this study module was also called "the deepening and widening of the world view". Under each theme one integrating course was created which consisted several school subjects and subject experts. The idea was that the students and subject expert would work together in collaborative way under the common integrating theme. The group was responsible for the planning and implementation of the contents and working procedures of each course. The first two courses of the study module ("Sustainable development" and "Human being") were conducted during the second and third year. The last course ("Time") was conducted in the fourth year. The data of this study was collected from this last course.

During the course the group investigated the concept of time from multiple disciplinary perspectives, integrating the subject disciplines of mother tongue, handicrafts, history, and multiculturalism into their design. As a final product of their course the members of the group agreed to produce a short theater performance. Based on this initial plan they discussed the substantive idea of the theater play. They also discussed what kinds of expertise were needed in the course and invited appropriate experts (teacher educators) to join in the course. Four teacher educators representing the subject disciplines listed above participated in the course in the role of experts and supervisors.

The pre-service teachers and teacher educators all met as a group six times during the course. During the meetings general guidelines for the course were created, the students' plans and ideas were discussed, and the final product was evaluated. During the course the pre-service teachers also met at least once a week without the subject experts to discuss their progress on the task and to prepare for the next meeting with subject experts. Additionally, the students met some of the subject experts privately a few times during the course.

\section{Data Collection and Analysis}

Our data corpus consists of six video-recorded meetings in which only the pre-service teachers were present, comprising a total of 12 hours of video. From this corpus, we selected the first officially scheduled two-hour meeting for detailed transcription and analysis. The selection was based on preliminary viewing of all the videos that resulted in content logs (Jordan \& Henderson, 1995). We decided to focus on phases in which the pre-service teachers conducted planning and talked about planning. Earlier studies of expansive learning (e.g., Engeström, 2008, pp. 118-168) have demonstrated that features of expansive learning may be found when participants face an open-ended problem solving task, such as a need to plan something that is new for them. Since an analysis combining the framework of expansive learning actions and the framework of types of interaction was new and needed to be carefully tested as a methodological solution, we decided to concentrate on a single meeting. Focusing on a single meeting runs the risk that no meaningful mini-cycle of expansion is accomplished in such a limited time. Our preliminary viewing of the video data convinced us that this meeting was rich in learning actions and types of interaction and would be worth a detailed analysis in spite of the risk. The procedure of our data analysis consisted of four steps, schematically depicted in Figure 2. This Figure 2 is a summary of the steps of our analysis, not a representation of the conceptual 
structure of expansive learning. The four steps depicted in Figure 2 stem from our specific research questions. They are not meant to represent a general procedure to be applied in all analyses of expansive learning.

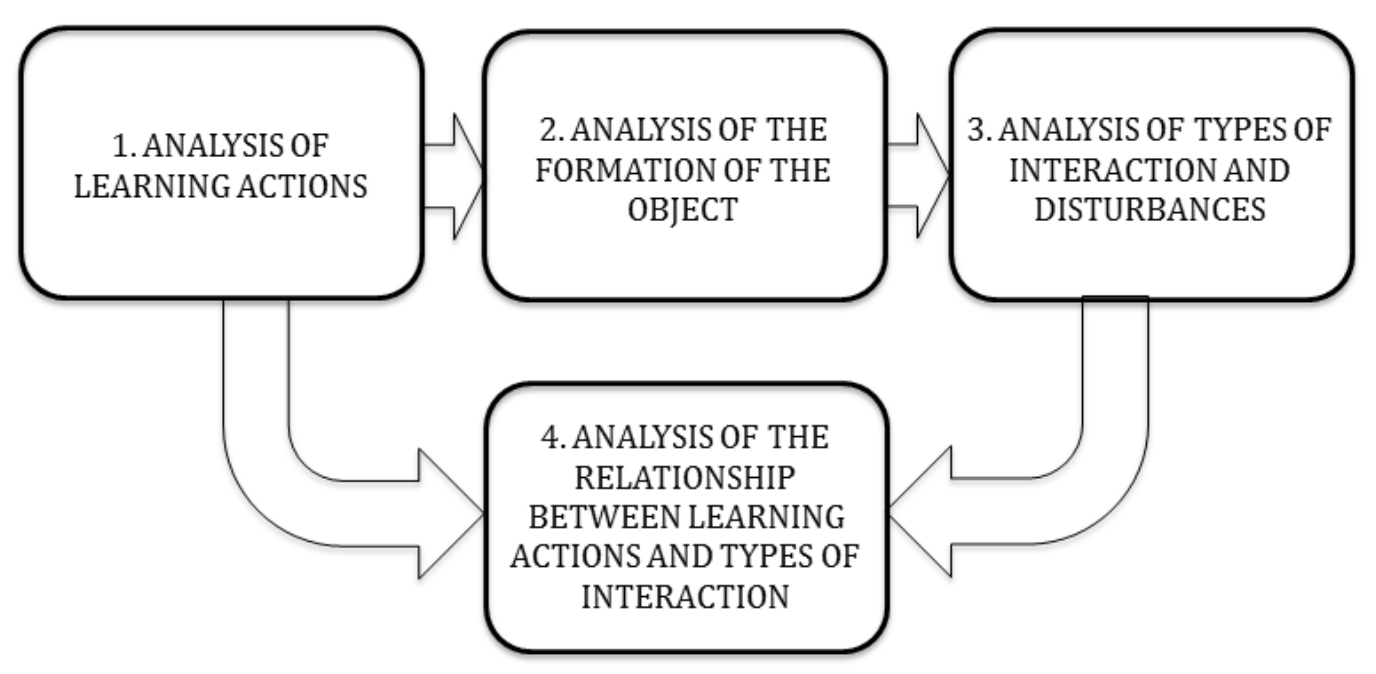

Figure 2. Steps in the analysis of the data.

As a first step, we identified expansive and non-expansive learning actions in the meeting by (a) discerning the topical episodes based on their substantive contents, (b) analyzing the turns of talk within each topical episode in terms of actions and formulating a preliminary description of the actions, and (c) specifying the epistemic function of each action in the stream of learning actions. A learning action typically consisted of an interactive effort that contained more than one turn of talk but was usually shorter than a topical episode. Learning actions which did not correspond to the characteristics of any of the expansive learning actions and did not contain an attempt at questioning or explicating the shared object were categorized as non-expansive.

As a second step, we examined the succession of the learning actions in relation to the phases of the formation of the object. In other words, we checked which object the learning actions were directed at and what possible phases and turning points emerged in the formation of the object.

As a third step, we identified types of interaction in the data. An interaction type for each topical episode was tentatively named by examining the nature of exchanges in the episode and by identifying possible shared or individual objects of the participants. Next disturbances, that is, unintentional deviations from the script, were identified. Finally, points of transition from one type of interaction to another were examined in greater detail.

As a fourth step, to investigate the relationship between expansive learning actions and types of interaction, we brought the two analyses together. Next we show briefly with help of transcript excerpts how the three analysis methods mentioned above were applied on the data.

The students had agreed earlier that the main task for the course would a preparation of a short theater performance. Thus the students needed to write together a script for the theater play. In the next excerpt (Table 2) the students are discussing whether some common frames or guidelines are needed for the writing of the script. 
Table 2

An example the analyses of learning actions, types interaction and object formation

\begin{tabular}{|c|c|c|c|c|}
\hline Turns & Transcription & $\begin{array}{l}\text { Learning } \\
\text { action }\end{array}$ & $\begin{array}{l}\text { Type of } \\
\text { Interaction/ } \\
\text { Disturbance }\end{array}$ & $\begin{array}{l}\text { Object } \\
\text { formation }\end{array}$ \\
\hline 145 & $\begin{array}{l}\text { Mark: Shall we frame this in some way, I mean, if we go backwards } \\
\text { in time [in the story], sort of... }\end{array}$ & $\mathrm{AE}$ & Dist/CoopA & TO \\
\hline 146 & $\begin{array}{l}\text { Ann: Well, somebody can go ten years forward [in his/her story], if } \\
\text { Tina goes } 50 \text { years forward [in her story]. }\end{array}$ & $\mathrm{AE}$ & Dist/CoopA & TO \\
\hline 147 & $\begin{array}{l}\text { John: I'm also getting curious whether we have some common } \\
\text { guidelines or does everybody just choose "I will do this" or "I will do } \\
\text { that." Is our plan again that I choose it [the story] to take place in ten } \\
\text { years' time, and you choose it [your story] to take place after } 20 \\
\text { years. I don't know if it makes any sense. }\end{array}$ & $\mathrm{AE}$ & Dist/CoopA & TO \\
\hline 148 & Mark: (inaudible) & $\mathrm{AE}$ & Dist/CoopA & TO \\
\hline 149 & $\begin{array}{l}\text { John: I tried to suggest this system with the panelists [teacher } \\
\text { educators]. Or are we going to go through any of those reference } \\
\text { points with the panelists. That is a principled decision... }\end{array}$ & $\mathrm{AE}$ & Dist/CoopA & TO \\
\hline 150 & $\begin{array}{l}\text { Ann: How about if one just begins working [his or hers own story] } \\
\text { even if we others don't know what the time or the place [where the } \\
\text { story is situated]. If one could begin to create a personality or a role } \\
\text { for the main character. Then one does not necessarily need the time. } \\
\text { It could the way to go forward with producing the fictional text. }\end{array}$ & $\mathrm{AE}$ & Coord & TO \\
\hline
\end{tabular}

Legend: $\mathrm{AE}=$ analyzing: actual-empirical analysis; $\mathrm{Dist}=$ disturbance; $\mathrm{CoopA}=$ cooperation attempt; $\mathrm{TO}=$ transitional object

In this excerpt we identified one expansive learning action, namely actual-empirical analysis. During the learning action of analysis the painstaking process of problem finding and problem definition took place. Mark (turn 145) highlighted the problem that common frames are needed for the joint writing process. John (turn 147) emphasized that it might be problematic if everybody could choose freely the topic for their writing. In the analysis of interaction this excerpt was seen as a disturbance. The group's meeting started with coordination-type of interaction; each participant was concentrating on presenting their own idea and perspective. This coordination was disturbed as two participants, Mark and John, made a cooperation attempt by challenging the group's initial plan which they saw as too vague and non-specific. The cooperation attempt of Mark and John did not get response from other participants and the interaction returned to the coordination mode (turn 150). In the analysis of object formation we concluded that in this excerpt the initial diffuse object, named "Time", was already transformed into the transitional object named "Theater play".

In the next excerpt (Table 3) the student group was talking about problems of collaboration and found a possible explanation from the group's shared history. In our analysis of expansive learning this was identified to be a learning action of reflecting on the process. The student group was evaluating its own activity in a reflective way. In the analysis of interaction this sequence was identified to represent communication. John (turn 456) was tracing the problems in collaboration to the beginning of the group's life cycle, a phase in which the principle of individual freedom of choice dominated. John recognized that this habit of freedom of choice had now become a problem when the group needed to plan a collective project. 
The initial way of working now became an obstacle to interaction and collaboration. In the analysis of object formation, the transitional object "Theater play" was identified also in this excerpt.

Table 3

An example the analyses of learning actions, types interaction and object formation

\begin{tabular}{|c|c|c|c|c|}
\hline Turns & Transcription & $\begin{array}{c}\text { Learning } \\
\text { action }\end{array}$ & $\begin{array}{c}\text { Type of } \\
\text { Interaction/ } \\
\text { Disturbance }\end{array}$ & $\begin{array}{l}\text { Object } \\
\text { formation }\end{array}$ \\
\hline 456 & $\begin{array}{l}\text { John: Just recently we were so excited and explaining to the Lions } \\
\text { [another student group] how we had such great freedom in the } \\
\text { beginning. But however, that freedom is causing us problems now. } \\
\text { Although there is lots of freedom in this unit, it is unlikely that } \\
\text { anyone in this unit will have as much freedom as we had. Although, } \\
\text { this [freedom] is a positive thing in many ways, one negative aspect } \\
\text { [of it] is probably that we have sort of become the conquerors of the } \\
\text { world, who can do whatever they feel like - and "that's how I'm } \\
\text { going to do it" }\end{array}$ & $\mathrm{R}$ & Com & TO \\
\hline 457 & Tina: And whenever I'm up to it... & $\mathrm{R}$ & Com & TO \\
\hline 458 & $\begin{array}{l}\text { John: And when I'm up to it. And if I'm not up to it, nobody can tell } \\
\text { me that "you have to do it" }\end{array}$ & $\mathrm{R}$ & Com & TO \\
\hline
\end{tabular}

Legend: $\mathrm{R}=$ reflecting on the process; $\mathrm{Com}=$ communication; $\mathrm{TO}=$ transitional object

\section{Expansive learning actions}

In our data, we could identify all the learning actions of the expansive cycle except consolidating the new practice. The absence of consolidation is an obvious consequence of focusing on a single meeting: the modeling of a new solution had just begun and the initial idea had not matured enough yet to be consolidated and generalized into a new and stable practice. The results of the analysis of learning actions are summarized in Table 4.

The meeting started with an episode that did not correspond to the characteristics of any of the expansive learning actions. In this episode, the pre-service teachers discussed practical preparations for the next meeting with subject experts without an attempt at questioning or explicating the object. We gave this non-expansive action the tentative name maintaining the existing practice to describe its character without making any particular theoretical assumptions. The notion of existing practice refers here to routine practices of planning and preparation within teacher education. 
Table 4

Types and frequencies of expansive and non-expansive learning actions in the pre-service teachers' meeting

\begin{tabular}{lcc}
\hline Type of learning action & Number of learning actions & Number of turns of talk \\
\hline${\text { Maintaining the existing } \text { practice }^{\mathrm{a}}}^{\text {Questioning }}$ & 1 & 65 \\
Analyzing: Actual-empirical analysis & 1 & 8 \\
Analyzing: Historical analysis & 8 & 243 \\
Modeling a new solution & 1 & 2 \\
Examining the new model & 2 & 6 \\
Implementing the new model & 5 & 45 \\
Reflecting on the process & 8 & 127 \\
Different topic & 5 & 49 \\
Total & - & 258 \\
\hline
\end{tabular}

${ }^{a}$ Non-expansive learning actions are indicated by italics.

${ }^{\mathrm{b}}$ Conversation not related to the group's assignment (planning of the course).

As Table 4 shows, the most common expansive learning actions in the meeting were analyzing, specifically actual-empirical analysis, and implementing the new model; both occurred 8 times. The large number of actions and speaking turns related to actual-empirical analysis indicates that problem finding and problem definition played a central role in the meeting - an emphasis to be expected at the beginning of the expansive learning process. Interestingly enough, implementing the new model, reflecting on the process, and examining the new model formed the other dominant block of expansive learning actions. This indicates that instead of only focusing on the early learning actions of the expansive cycle, the group went indeed through an entire mini-cycle of expansive learning in the meeting. On the other hand, the low frequencies of questioning and modeling the new solution indicate that perhaps the shared object constructed in this first meeting was still only very preliminary and would invoke further questioning and re-modeling as the process went on.

Frequencies of expansive learning actions tell only a part of the story. The more important issue is the way in which the learning actions flow forward and form a meaningful order within a session. By meaningful order we refer to the general directionality of the theoretically formulated expansive cycle (see Engeström et al., 2013).

In Table 5 we give a condensed overview of the progression of expansive learning actions and their contents in the meeting. 
Table 5

Succession of expansive and non-expansive learning actions and their contents in the pre-service teacher group's meeting

\begin{tabular}{|c|c|c|}
\hline $\begin{array}{l}\text { Turns of } \\
\text { talk }\end{array}$ & Contents & $\begin{array}{l}\text { Learning } \\
\text { action }\end{array}$ \\
\hline $1-65$ & Practicalities concerning the next meeting with subject experts are discussed & $m e p^{\mathrm{a}}$ \\
\hline 66-73 & Tina: "Have we completely forgotten the starting point?" & Q \\
\hline 74-80 & Planning of the theater play begins & $\mathrm{AE}$ \\
\hline 81-98 & Division of instructional resources for the course & $\mathrm{AE}$ \\
\hline 99-154 & Agreement on the joint writing task & $\mathrm{AE}$ \\
\hline $155-173$ & Setting the story in the future & $\mathrm{AE}$ \\
\hline $174-175$ & The contents of the previous course considered as starting point & HA \\
\hline $176-225$ & Setting the story in the future (continued) & $\mathrm{AE}$ \\
\hline $226-281$ & Disagreement whether story should be situated in future or in history & $\mathrm{AE}$ \\
\hline $282-312$ & Negotiation on the starting point of the story ends up in deadlock & $\mathrm{AE}$ \\
\hline $313-315$ & $\begin{array}{l}\text { Ann suggests that the theme "making a choice" should be in everyone's story; she gets no } \\
\text { response }\end{array}$ & M \\
\hline $316-321$ & Creation of a unified story seems impossible & $\mathrm{AE}$ \\
\hline $322-324$ & Ann demands again a response to her suggestion; this time other participants are responding & M \\
\hline $325-343$ & $\begin{array}{l}\text { Ann's idea is accepted and discussion begins on how to include "making a choice" in each } \\
\text { participant's story }\end{array}$ & E \\
\hline 344-354 & $\begin{array}{l}\text { Participants discuss the group's way of working and state that collaboration is possible but it } \\
\text { takes time }\end{array}$ & $\mathrm{R}$ \\
\hline $355-358$ & Need for the virtual learning environment (FLE) to make things work is acknowledged & I \\
\hline 359-362 & $\begin{array}{l}\text { Sheila states that it is problematic if everyone can still write what one wants without any } \\
\text { common frame }\end{array}$ & $\mathrm{R}$ \\
\hline $363-372$ & $\begin{array}{l}\text { Realization that experts of different fields have different perspectives on important moments } \\
\text { in history }\end{array}$ & $\mathrm{E}$ \\
\hline $373-378$ & $\begin{array}{l}\text { Sheila emphasizes the need for a common starting point for the writing; the themes/topics are } \\
\text { too general to guide the writing process }\end{array}$ & $\mathrm{R}$ \\
\hline 379-384 & $\begin{array}{l}\text { Realization that important turning points in history should be discussed with teacher } \\
\text { educators }\end{array}$ & $\mathrm{E}$ \\
\hline $385-402$ & Decision that the shared plan should be moved into the virtual platform & I \\
\hline $403-416$ & Realization that preparing a theater play forces the participants to collaborate & $\mathrm{R}$ \\
\hline $417-429$ & Realization that jointly prepared questions for the expert interviews are needed & I \\
\hline $430-434$ & Decision to inform teacher educators about today's decisions & I \\
\hline $435-437$ & Decision: We have to start using the FLE [virtual learning environment] & I \\
\hline $438-447$ & Realization: What we teach today in school should be also relevant for the pupils in future & E \\
\hline $448-461$ & $\begin{array}{l}\text { John: We had such great freedom at the beginning and that freedom is causing us problems } \\
\text { now }\end{array}$ & $\mathrm{R}$ \\
\hline
\end{tabular}


461-467 Decision: Tina should send her text to everybody

468-470 Realization: We have to decide whom to interview

[471-713] [Talk about subject matters unrelated to the planning of the next meeting and the course]

714-787 Organizing the expert interviews and sending an email to subject experts

[788-802] [Talk about practicalities unrelated to the planning of the next meeting and the course]

Legend: mep = maintaining existing practice; $\mathrm{Q}=$ questioning; $\mathrm{AE}=$ analyzing: actual-empirical analysis; $\mathrm{HA}=$ analyzing: historical analysis; $\mathrm{M}=$ modeling a new solution; $\mathrm{E}=$ examining the new model; $\mathrm{I}=$ implementing the model; $\mathrm{R}=$ reflecting on the process; $\mathrm{dt}=$ different topic

${ }^{a}$ Non-expansive learning actions are indicated by italics.

Table 5 shows that the learning actions of the expansive cycle were taken by and large in the order predicted in the theory. To be sure, there were iterations, such as the sequence analyzing $\rightarrow>$ modeling $\rightarrow$ analyzing $\rightarrow$ modeling in turns 282-324. Also, reflecting on the process was interspersed among actions of examining and implementing the new model in the latter part of the meeting. Such iterations are not incompatible with the general model of the expansive cycle, but they represent an interesting challenge for further research.

It seems that the expansive mini-cycle was in this case composed of two main parts. We might call these (1) working on the problem (turns 66 to 324) and (2) working on a new model (turns 325 to 470 and turns 714 to 787). During the first part, problem finding and problem definition and formulation of a tentative solution dominated the discussion. This included the learning actions of questioning, actualempirical and historical analysis, and modeling a new solution. During the second part, the solution idea was refined into practical applications and procedures. This included the learning actions of examining and implementing the new model and reflecting on the process. The learning action modeling a new solution formed a turning point and bridging phase between the two main parts.

Overall, the succession of learning actions in Table 5 looks almost like a perfect expansive minicycle. However, closer scrutiny reveals that the cycle is not at all perfect. For this scrutiny, we need to trace the steps of the formation of the object.

\section{Phases of object formation}

The initial object of the work of the group was "time". This was in general terms agreed upon in the group already in the spring. In the fall, before starting the officially scheduled meetings for planning and implementing the course, the pre-service teachers had an informal meeting in a café in which they came up with an idea of producing a small theater play as an outcome of the course.

In their first officially scheduled meeting, the first non-expansive learning action, maintaining the existing practice (turns 63 to 65, Excerpt 1), represents routine-like planning. It consisted of discussion about how to proceed, with no reference to the shared object. The pre-service teachers articulated their object first in terms of the theater play (turns 66 to 69 ).

\section{EXCERPT 1}

63 Sheila: Have we planned at all the agenda for the next meetings? How about if everybody would prepare something for a certain meeting. How many are we... five?

64 John: Six... Tom [member of the group who is absent].

65 Sheila: Tom, so we are six all together. How about if one or two people take charge of one meeting. Or if it's well structured, I don't mind If everyone would prepare for a certain meeting a presentation. The we would use 
three meeting for this and then we will have two presentations for each meeting. It [a meeting] is three hours, so it means one and half hours for each person.

66 Tina: Have we completely forgotten the starting point, or forgotten the idea that came up last time? Well, you [addressing Sheila] did not hear all of it. Were you taking care of some other business at the time?

67 Sheila: Could you explain briefly your understanding of it?

68 Tina: We were developing that idea of the theater play.

69 Sheila: Hm.

In turn 66, Tina challenged the group's routine-like mode of working and reminded the participants of a shared starting point discussed in a preceding informal preliminary meeting: "Have we completely forgotten the starting point, or forgotten the idea that came up last time?" This is the first articulation of the group's emerging object: the theater play. However, the emerging object remained quite vague, as if a formal shell to be filled with contents. It was not yet a substantive principle or a "germ cell". In this sense, we may characterize it as a transitory object.

The second turning point in the formation of the object took place much later, starting from turn 313 (Excerpt 2). The pre-service teachers had discussed the theater play idea for a lengthy period, circling around the idea that each participant would produce his or her own story and pondering on the difficulty of providing coherence and continuity to a text produced this way. Ann then initiated actions of modeling in which the participants articulated the second version of their emerging consciously shared object. In this phase, the new object took the shape of the principle of "making a choice" - potentially a substantive germ cell for a new model.

\section{EXCERPT 2}

313 Ann: I might have a theme to suggest.

314 Sheila: Go ahead.

315 Ann: What if there would be a shared theme of "making a choice" in all of these [individual stories]? That could be done in different ways. The consequences of the choice can be seen later in how the story develops. Even though this can be difficult to execute. Still, even if characters and situations [in the individual stories] were different, the "making of a choice" would be a connecting link [between the individual stories].

$[\ldots]$

322 Ann: Now I would like to hear comments about my recent idea. Instead of just everybody being silent, I would like to hear some responses like: "I'm not sure...", or "Yes, sounds good...", or "I would like to...".

323 Sheila: Would you explain it briefly one more time?

324 Ann: What we should decide now is the connecting element [between the stories]; if everyone starts to write on their own, the connecting element could be making a choice. In every story the theme would be making a choice. This would be visible always, as we move further in time...

325 Tina:... It is choices that have impact...

326 John: ... They are the ones that have impact.

327 Mark: ... How would we establish continuity between persons, or is it just any act of making a choice?

328 John: That's just what we should create together.

329 Ann: The continuity is in the fact that in what comes we will see the consequences of the previous choice.

330 John: And those of the previous, previous choices.

331 Tina: Like for example my choices.

Excerpt 2 is important in that the vague and diffuse initial object - the notion of time - and the formal transitional object of a theater play were now turned into a much more focused idea, that of making a choice. The notion of choice was connected to the original notion of time by realizing that choices have consequences that are revealed in time: "in what comes we will see the consequences of the previous choice."

From Table 5 (Section 6) one might infer that the new object, making a choice, was systematically examined and implemented from this point on. However, this was not the case. The phase that followed immediately after the examination of the newly articulated object of making a choice (turns 344 to 354) consisted of reflecting on the process, specifically on the possibility of genuine collaboration - but no reference was made to the idea of making a choice. The next phase (turns 355 to 358) focused on the 
implementation of the plan by means of the virtual learning environment FLE - again, with no reference to making a choice. In fact, until the very end of the meeting, the object of making a choice was not anymore mentioned by the participants. The actions of examining and implementing the model actually referred to the transitional object of the theater play, not to the principle of making a choice. The latter was as if forgotten, and the process circled back to the transitional object. In other words, the proposed germ cell was encapsulated, not elaborated on and expanded. The stepwise formation of the object in this meeting may be summarized with the help of Figure 3.

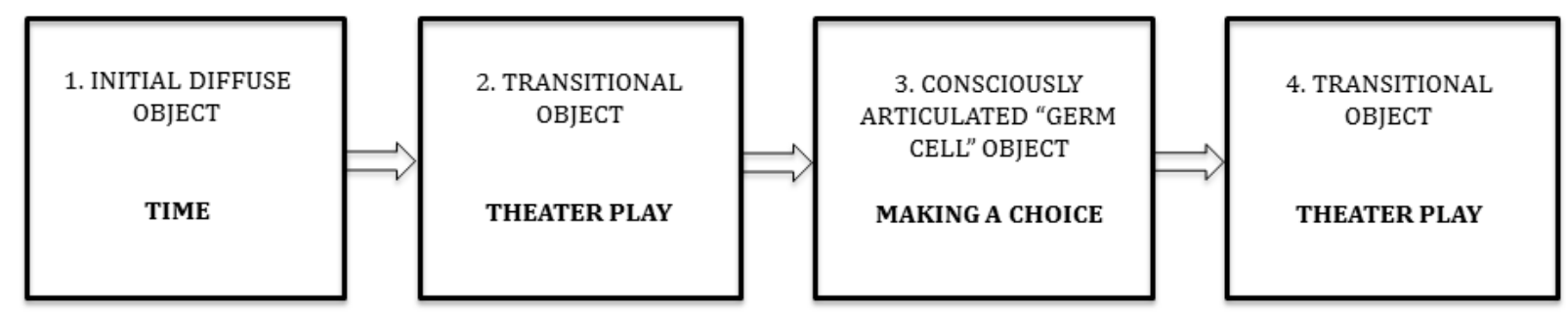

Figure 3. Actual steps in the formation of the object in the pre-service teachers' meeting.

The steps depicted in Figure 3 testify to the iterative and non-linear character of expansive learning. In our previous study conducted in a library context (Engeström et al., 2013), we identified such an iterative and non-linear loop of expansive learning cycle. In the first six sessions the occurrence of learning actions were in line with the general sequence of theoretical model of the expansive learning but in the last two sessions the expansive learning cycle started again from the beginning. In similar way, object formation does not follow the ideal-typical phases as formulated in Figure 1 (Section 2.3), and sometimes process can collapse and turn backwards.

A single meeting is not likely to produce a neat full-fledged expansive cycle: "miniature cycles of innovative learning should be regarded as potentially expansive" (Engeström, 2008). The potential is realized - or not realized - in the longer process.

\section{Types of interaction}

There are only few studies which have applied the framework of three types of object-oriented interaction. These studies have demonstrated (Engeström, 2008, pp. 49-85; Saari, 1995; de Lange, 2011) that the most common type of interaction is coordination, the second most common is cooperation, and the rarest type is communication. Further, these studies also revealed the important role of disturbances in the analysis of types of interaction.

We identified all three main types of interaction - coordination, cooperation, and communication in our data. We also found three phases of pseudo-cooperation. As shown in Table 6, the most common type of interaction was coordination, comprising 227 turns of talk. 105 turns represented cooperation, and 47 turns pseudo-cooperation. Communication occurred only in 10 turns. This low number of communication turns indicates that reconceptualizing the script and mode of interaction in relation to the shared object of activity was very challenging for the participants. 
Table 6

Types of interaction in the meeting of the pre-service teachers' group

\begin{tabular}{lcc}
\hline Type of interaction & Phases & Turns \\
\hline Coordination & 5 & 227 \\
Cooperation & 6 & 105 \\
Pseudo-cooperation & 3 & 47 \\
Communication & 1 & 10 \\
Total (types of interaction) & 15 & 389 \\
Different topic & 2 & 258 \\
\hline
\end{tabular}

As pointed out above, a transition from one type of interaction to another often passes through a short phase of disturbances. Disturbances may lead to disintegration, contraction, or expansion in the process. In our data, we identified a number of conflicts. In addition to those, we also examined cooperation attempts and communication attempts as disturbances. The frequencies of these disturbance types are presented in Table 7.

Table 7

Types and frequencies of disturbances in the student group's meeting

\begin{tabular}{lcc}
\hline Disturbance & Episodes & Turns \\
\hline Conflict & 3 & 10 \\
Cooperation attempt & 7 & 40 \\
Communication attempt & 5 & 32 \\
Total & 15 & 82 \\
\hline
\end{tabular}

Table 8 presents the temporal succession of the types of interaction in the meeting. The idea of theater play as a transitional object was invoked in turns 66 to 73 . The subsequent turns 74 to 144 represent a return to coordination. The participants brought up different resource issues (time, help from teacher educators, the virtual learning environment) that did not generate a common thread and problem to be jointly tackled. Questions about the allocation of time for the preparation of the theater play were raised and ruminated about but not answered: "But how much time do we have to reserve for it [preparing of the theater play], extra days, for the work it out, because it takes...?" (turn 71) "How much time have we reserved? We have booked Fridays from nine to three. After the panel meetings there is always time and..." (turn 81). This does not look very efficient; one might argue that it looks more like discoordination than coordination. However, the standard script of planning in meetings is often indeed inefficient, an example being prolonged episodes in which the participants try to agree on the date and time of the next meeting, each one bringing up disconnected concerns and constraints that make the decision-making look rather absurd. This way 
coordination in meetings quite often comes close to its own limits; such episodes could easily collapse into discoordination or erupt into open conflict.

As already noted in the discussion of Table 5 (Section 6), the group's interaction seems to have consisted of two main parts. We might call the first part (turns 1 to 324) "coordinative interaction" and the second part (turns 325 to 470) "cooperative interaction". Characteristic to the first part was that the transitional object of theater play did not function as a truly shared object. The first part contained also a pseudo-cooperation phase and several cooperation attempts interpreted as disturbances.

The second part is more problematic. There was a notable increase in cooperation and communication attempts. But as we know from the preceding section, after the brief phase of cooperation based on the object of making a choice, the remaining phases of cooperation and communication attempts were actually focused on the transitional object of theater play. In this light, the second part of the meeting was not simply continuation of the first part but rather circling back to the earlier object.

Table 8

Types of interaction and disturbances in the student group's meeting

\begin{tabular}{ll}
\hline Turns Contents & $\begin{array}{l}\text { Type of interaction } / \\
\text { Disturbance }\end{array}$ \\
\hline
\end{tabular}

1-65 Practicalities concerning the next meeting with subject experts are discussed Coordination

66-73 A disagreement between the participants of the common starting point

Cooperation attempt ${ }^{\mathrm{a}}$

74-144 A discussion of how to proceed with a joint preparation of a theater play Coordination

145-149 A criticism that the guidelines for the joint writing task are missing Cooperation attempt

150-154 A suggestion that the same protagonist in every story could be a link between Coordination different stories

155-164 Taking Tina's story as a common starting point

Pseudo-cooperation

165 Is it possible to have something else than just science fiction in the story

Cooperation attempt

166-178 A development of the idea of the story that takes place in future

Pseudo-cooperation

179-189 A disagreement of how much one should put emphasis in future in his or her story

190-213 A development of the story situated in future continues

Cooperation attempt

214-222 Should we have a same central character in every story?

Pseudo-cooperation

223-225 John does not want to situate his story in the future

Cooperation attempt

226-311 Unsuccessful attempts trying to find connecting theme for the shared story

Conflict

Coordination

312 Seems impossible to write a shared story

Conflict

313-315 Ann is suggesting that in everyone's story should be a one unified theme, which is "making a choice" but did not get response

Cooperation attempt 
316-321 Seems that participants only want to work individually without binding structure

322-324 Ann demands again a response for her suggestion more determined way and this time other participants are responding

325-343 Ann's idea is accepted and discussion begins how to connect making a choice in each participant's story

344-351 Participants discuss the group's way of working and state that collaboration is possible but it takes time

352-358 John says that one needs to follow others work too if he/she wants that his/her story works

359-362 Integrating theme is missing

363-372 Chosen perspectives for the story can sometimes be too narrow

373-378 Sheila: our themes are topics are too general to guide our writing process

379-406 Different ideas concerning joint story writing are considered

407-416 Previously we did not have a common goal which forces us now to collaborate

Conflict

Cooperation

Communication attempt

Cooperation

Communication attempt

Cooperation

Communication attempt

Cooperation

Communication attempt

417-447 Preparing interviews; informing teachers; getting a virtual learning platform; visioning pupils' needs in future

448-451 Earlier we use to have only individual goals?

Communication attempt

452-461 John sees that in the early-stage of group's work it was given so much

Communication freedom that collaboration is now difficult

461-470 Tina's story is chosen as one starting point and the interviews of the experts are organized

[471-713] [Talk about subject matters unrelated to the planning of the course]

[Different topic]

714-787 Organizing the expert interviews and sending an email to subject experts

Coordination

[788-802] [Talk about practicalities unrelated to the planning of the course]

[Different topic]

${ }^{a}$ Disturbances are indicated by italics.

\section{Dynamics between learning and interaction}

As a result of the analysis of expansive learning actions, the meeting was tentatively divided into two main parts, "working on a problem," and "working on a model". In a similar way, in the analysis of types of interaction, the meeting was divided in two main parts, "coordinative interaction" and "cooperative interaction". The transition from the first part to the second part took place at the same point in both analyses. 
As the two analyses were merged in Table 9 it was possible to divide the meeting into three parts. The first part of the meeting may be called "Coordinated working on a problem", the second part "Transition from coordinated working to cooperative working", and the third part "Cooperative working on a model".

Table 9

Merged analyses of learning actions and types of interaction

\begin{tabular}{|c|c|c|c|}
\hline \multirow{2}{*}{\multicolumn{2}{|c|}{ Analysis of expansive learning }} & \multicolumn{2}{|r|}{ Analysis of interaction } \\
\hline & & Turns & Type of interaction / Disturbance \\
\hline $01-65$ & Maintaining the existing practice & $01-65$ & Coordination \\
\hline
\end{tabular}

First part: "Coordinated working on a problem" (turns 66-324)

\begin{tabular}{clcl}
\hline $66-73$ & Questioning & $66-73$ & Cooperation attempt ${ }^{b}$ \\
$74-80$ & Actual-empirical analysis & $74-144$ & Coordination \\
$81-98$ & Actual-empirical analysis & $\mid$ & $\mid$ \\
$99-154$ & Actual-empirical analysis & $\mid$ & $\mid$ \\
$\mid$ & $\mid$ & $145-149$ & Cooperation attempt \\
$\mid$ & $\mid$ & $150-154$ & Coordination \\
$155-173$ & Actual-empirical analysis & $155-164$ & Pseudo-cooperation \\
$\mid$ & $\mid$ & 165 & Cooperation attempt \\
$174-175$ & Historical analysis & $166-178$ & Pseudo-cooperation \\
$176-225$ & Actual-empirical analysis & $179-189$ & Cooperation attempt \\
$\mid$ & $\mid$ & $190-213$ & Pseudo-cooperation \\
$\mid$ & $\mid$ & $214-222$ & Cooperation attempt \\
$\mid$ & | & $223-225$ & Conflict \\
$226-281$ & Actual-empirical analysis & $226-311$ & Coordination \\
$282-312$ & Actual-empirical analysis & 312 & Conflict
\end{tabular}

Second part: "Transition from coordinated working to cooperative working" (turns 313-324)

$\begin{array}{llll}313-315 & \text { Modeling a new solution } & 313-315 & \text { Cooperation attempt } \\ 316-321 & \text { Actual-empirical analysis } & 316-321 & \text { Conflict } \\ 322-324 & \text { Modeling a new solution } & 322-324 & \text { Cooperation attempt }\end{array}$

Third part: "Cooperative working on a model" (turns 325-470)

$\begin{array}{llcl}325-343 & \text { Examining the new model } & 325-343 & \text { Cooperation } \\ 344-351 & \text { Reflecting on the process } & 344-351 & \text { Communication attempt } \\ 352-354 & \text { Examining the new model } & 352-358 & \text { Cooperation } \\ 355-358 & \text { Implementing the model } & \mid & \mid \\ 359-362 & \text { Reflecting on the process } & 359-362 & \text { Communication attempt } \\ 363-372 & \text { Examining the new model } & 363-372 & \text { Cooperation }\end{array}$


373-378

379-384

$385-402$

403-416

417-429

430-434

435-437

438-447

448-461

|

461-467

468-470

[471-713]

714-787

[788-802]
Reflecting on the process

Examining the new model

Implementing the model

Reflecting on the process

Implementing the model

Implementing the model

Implementing the model

Examining the new model

Reflecting on the process

\section{।}

Implementing the model

Implementing the model

[Different topic]

Implementing the model

[Different topic]
373-378

379-406

407-416

417-447

448-451

452-461

461-470

[471-713]

714-787

[788-802]
Communication attempt

Cooperation

Communication attempt

Cooperation

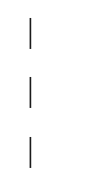

Communication attempt

Communication

Cooperation

[Different topic]

Coordination

[Different topic]

${ }^{a}$ Non-expansive learning actions are indicated by italics.

${ }^{\mathrm{b}}$ Disturbances are indicated by italics.

Table 9 would seem to indicate that as an expansive learning process moves epistemically from questioning to analysis, modeling, implementation and reflection on the process, it also moves interactionally from coordination to cooperation and at least attempted communication. On the other hand, there is no deterministic or mechanical correspondence between specific learning actions and specific types of interaction. Epistemic actions that serve an expansive function from the point of view of the entire cycle may be performed in a coordinated manner that makes them look rather unproductive within their own limited confines. And superficially productive forms of interaction may in a closer analysis turn out to be phases of pseudo-cooperation that serve to avoid the core issues rather than tackle and solve them.

In Table 9, there is a long phase (74-312) containing several learning actions of actual-empirical analysis and one learning action of historical analysis. This phase consists of different types of interaction (coordination and pseudo-cooperation) and several disturbances (cooperation attempts and conflicts) which shows that mechanical correspondence between specific learning actions and specific types of interaction does not exist. In Section 8, part of this phase (turns 74-144) is analyzed more detailed and it is possible to see how joint planning looks inefficient and unproductive as the participants brought up different resource issues that did not generate a common thread and problem to be jointly tackled.

However, in our data the learning actions of questioning were typically interpreted as cooperation attempts. The learning actions of actual-empirical analysis were interactionally more heterogeneous, containing coordination and pseudo-cooperation types of interaction as well as several cooperation attempts and conflicts. The learning actions of modeling were typically interpreted as cooperation attempts, whereas the learning actions of examining and implementing the new model were typically interpreted as cooperation. The learning actions of reflecting on the process were typically categorized as communication attempts or, in one case, as communication.

Probably the most important lesson from the integrated analysis is the importance of transitions and disturbances. These may be small in terms of time and number of speaking turns, but they are crucial for the understanding of the dynamics of the learning process. The fact that the short sequence of turns 313 to 324 was identified as a turning point in both analyses testifies to this. 


\section{Conclusions}

In this paper, we have examined the theory of expansive learning (Engeström, 2015) as a conceptual and methodological framework for understanding open-ended and problem-based collaborative learning among Finnish pre-service teachers. Our study was focused especially on two aspects of expansive learning, namely types and sequences of expansive learning actions (e.g., Engeström \& Sannino, 2010) and types and sequences of object-oriented interaction (Engeström, 2008; Fichtner, 1984; Raiethel, 1983).

The task of the paper is primarily methodological. We believe that cultural-historical activity theory needs to be turned into methods and procedures of systematic empirical analysis. Therefore, the aim of the paper is to develop methodology for analyzing dynamics of expansive learning. A new methodological framework created in this study is tested in the analysis of planning meeting of a pre-service teacher group.

Our research questions are driven by our methodological interest in examining the analytical potential of the framework of expansive learning with data from a learning context which was not deliberately designed to follow the guidelines of expansive learning. For this reason, our methodological research questions are accompanied by auxiliary substantive questions. The substantive questions may be read as vehicles with which the methodological questions are approached and made concrete.

The first methodological question of our study was: How does the conceptual framework of expansive learning actions work in the analysis of data from a single session of collaborative learning not deliberately designed to follow the guidelines of expansive learning? Our analysis showed that it is possible to apply the framework of expansive learning actions on a learning process confined to a single meeting in which expansive learning was not deliberately induced. This indicates that expansive learning can take place as a naturally occurring process also without formative interventions such as the Change Laboratory method (Engeström \& Sannino, 2010). Expansive learning processes can be analyzed in minute detail at the level of conversational turns and episodes, and an almost complete mini-cycle of expansive learning can be fulfilled during a single meeting.

Our analysis of expansive learning actions showed that an almost complete expansive learning cycle appeared in pre-service teachers' meeting. Six out of the seven learning actions of the expansive learning cycle appeared in the meeting in a meaningful order. Only the last expansive learning action, consolidating the new practice, was missing from the learning process - an outcome to be expected in light of the fact that our analysis was restricted to a mini-cycle accomplished within a single meeting. The low frequencies of the actions of questioning and modeling the new solution indicate that perhaps the shared object constructed in this first meeting was still only preliminary and would invoke further questioning and re-modeling as the process went on.

It seems that the mini-cycle of expansive learning consisted of two main parts, namely "working on a problem" and "working on a new model". The learning action of modeling a new solution functioned as a transition phase and bridge between the two main parts.

An interesting methodological finding is that learning actions in this meeting roughly followed the same order as the theory proposed. There were some iterative back-and-forth movements between learning actions of analyzing and modeling and in similar fashion with learning actions of examining, implementing and reflecting (see Engeström et al., 2013). This implies that learning actions may often take place in clusters in which the three first learning actions (questioning, analyzing and modeling) tend to occur together and, in a similar fashion, the next three learning actions (examining, implementing and reflecting) tend to occur together in iterative clusters. The two-part structure of the expansive learning cycle observed in this study also supports this finding.

Most theories of learning take the initial existence of a fairly clear problem, task or assignment as a given. It means that a phase of problem finding and definition of the object are not included in the focus of the analysis. In expansive learning this phase of "working on the problem" is essential. 
On the other hand, many theories of learning also ignore or exclude the actions of implementation. Jerome Bruner (1974, p. 233) pointed out that if we really want to study the conditions of learning, we need to follow our subjects far longer than is usual in laboratory experiments or test-driven classrooms. We need to see what the learners will do with their new insights, how knowledge is turned into actions. In this respect, the actions of implementation in the second part of the process of expansive learning are of utmost importance.

The second methodological question of our study was: How does the conceptual framework of the object formation work in the analysis of data from a single session of collaborative learning not deliberately designed to follow the guidelines of expansive learning? First, tracing the formation of the object is an indispensable methodological step in the analysis of expansive learning; and second, no matter how promising and powerful features of expansion we may find in a single learning session, a full assessment of such a mini-cycle requires an analysis of the entire multi-session learning process.

An ideal-typical process of expansive object formation moves from a routinized, fragmented or diffuse initial object to a consciously articulated and shared "germ cell" object, to an expanded concrete object (Figure 1, Section 2.3). The steps of object formation were different in the meeting we analyzed. The initial diffuse object ("time") was first transformed into a formal transitional object ("theater play"). Subsequently a potential "germ cell" object (the principle of "making a choice") was formulated by the participants - but it was abandoned and the participants returned to the transitional object (Figure 3, Section 7). In other words, what looked like a nearly perfect expansive mini-cycle turned out to be a more complex iterative process.

The third methodological question of our study was: How does the conceptual framework of types of object-oriented interaction work in the analysis of data from a single session of collaborative learning not deliberately designed to follow the guidelines of expansive learning? The framework of types of objectoriented interaction seems a promising method for opening up the dynamics of collaborative learning. The analysis of interaction shows clearly that the participants were not just focused on completing the task but also on their mutual interaction. The diversity of types of interaction found in the data indicates that different types of interaction are needed especially when students are trying to complete a vague and open-ended task.

All the three types of interaction - coordination, cooperation, and communication - occurred in the meeting of the pre-service teacher group. In addition, three phases of pseudo-cooperation were identified. This finding supports our conclusion that this form of learning was indeed rich and potentially powerful. We identified several transitions between types of interaction that were marked by disturbances, either in the form of conflicts or in the form of cooperation and communication attempts that were not picked up and sustained by other members of the group. Also the analysis of types of interaction indicated that the meeting was divided in two parts, "coordinative interaction" and "cooperative interaction". However, as pointed out above, the second part was not simply a continuation of the first part but more like circling back to the earlier transitional object.

The fourth methodological question of our study was: How does the integration of conceptual frameworks of expansive learning actions and types of interaction work in the analysis of data from a single session of collaborative learning not deliberately designed to follow the guidelines of expansive learning? A key methodological finding of this study is that while necessary, both epistemic learning actions and types of interaction are in themselves insufficient windows into expansive learning. What is needed as a connecting link is tracing steps in the formation of the object. In our study the analysis of the formation of the object revealed that what looked like a neatly linear expansive mini-cycle was in fact a more complex and iterative movement between different versions of the object. The true expansive potential of a mini-cycle can only be discovered by extending the time scale and scope of the analysis.

Our analysis indicates that as an expansive learning process moves epistemically from questioning to analysis, modeling, implementation and reflection on the process, it also moves interactionally from coordination to cooperation and at least attempted communication. On the other hand, there is no 


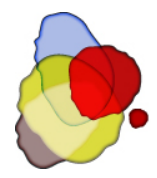

deterministic or mechanical correspondence between specific learning actions and specific types of interaction. The merging of the analysis of learning actions and the analysis of types of interaction led us to identify three parts in the meeting, namely "coordinated working on a problem", "transition from coordinated working to cooperative working", and "cooperative working on a model". Our integrated analysis highlights the importance of transitions and disturbances in expansive learning. These are often small in terms of time and number of speaking turns but crucial for the dynamics of the learning process. These kinds of findings concerning the complex character of expansive learning process have not been reported in previous studies and can thus serve as methodological supports for further research.

In the theory of expansive learning, contradictions are seen as the driving force of transformation (Engeström \& Sannino, 2010). Although our analysis did not specifically focus on contradictions, we can see in the pre-service teachers' meeting a pervasive tension between two scripts. The explicit script of the meeting was that of self-determined collaboration on a complex open-ended task, in which planning, design and implementation are unified. This script was challenged and interrupted by the traditional script of studying individually to complete given assignments, in which planning and design are reduced to technical and logistic arrangements. This tension seems to be behind the frequent disturbances observed in the meeting, and the group's difficulties in constructing a new shared object may be understood against this background.

The model of expansive learning is not a universal formula of phases or stages. One probably never finds a learning process that strictly follows the ideal-typical model of expansive learning. Whenever one examines or facilitates a learning process with the help of the model, one tests, criticizes and hopefully enriches the theoretical ideas of expansive learning. The theory of expansive learning has mainly been applied to large-scale transformations in activity systems, often spanning a period of 2 or 3 years. In this study, however, an expansive learning cycle was applied to analyze a single learning session, lasting only two hours. This raises a critical question: Can a mini-cycle of learning be characterized as expansive? Our analysis demonstrates that a mini-cycle of innovative learning can be, to some extent, expansive. The emergence of such mini-cycles does not itself guarantee that a larger expansive cycle takes place. Small cycles may remain isolated events, and the overall cycle of expansion may become stagnant or regressive or even fall apart. The occurrence of a full-fledged expansive learning cycle is challenging to achieve, and it typically requires concentrated effort of deliberate interventions. With these reservations in mind, the theory of expansive learning can be applied as a framework for analyzing small-scale innovative learning processes as well.

Moreover, our study contributes to research on learning and interaction in activity systems. Most studies on activity systems focus either on learning or on interaction, keeping the two relatively separate. Our aim was to produce a fine-grained analysis of the dynamics between expansive learning actions and types of interaction. The qualitative transition in the pre-service teachers' learning took place at the same point in both learning actions and in types of interaction. This indicates that cycles of expansive learning actions and progressions of types interaction are closely intertwined. Whether the dynamics and qualitative transitions are similar in other contexts as well, needs to be explored in future studies.

\section{Keypoints}

- A new methodological framework was created for analyzing dynamics of expansive learning.

- A new method is tested in the analysis of a planning meeting of a pre-service teacher group.

- Tracing the formation of the object is an indispensable methodological step in the analysis of expansive learning.

- The analysis of group's interaction highlights the importance of transitions and disturbances in expansive learning. 
This study offers a methodological lens for examining innovative forms of learning in various contexts.

\section{References}

Bereiter, C., \& Scardamalia, M. (1993). Surpassing ourselves: An inquiry into the nature and implications of expertise. Chicago: Open Court.

Bruner, J. S. (1974). Beyond the information given. London: George Allen \& Unwin Ltd.

Davydov, V. V. (1990). Types of generalization in instruction: Logical and psychological problems in the structuring of school curricula. Reston: National Council of Teachers of Mathematics.

Dillenbourg, P., Baker, M., Blaye, A., \& O'Malley, C. (1996). The evolution of research on collaborative learning. In H. Spada, \& P. Reimann (Eds.), Learning in humans and machines (pp. 189-211). Oxford: Elsevier Science.

Engeström, Y. (2008). From teams to knots: Activity-theoretical studies of collaboration and learning at work. Cambridge: Cambridge University Press.

Engeström, Y. (2015). Learning by expanding: An activity-theoretical approach to developmental research. Cambridge: Cambridge University Press.

Engeström, Y., Rantavuori, J., \& Kerosuo, H. (2013). Expansive Learning in a Library: Actions, Cycles and Deviations from Instructional Intentions. Vocations and Learning, 6 (1), 81-106. doi:10.1007/s12186012-9089-6

Engeström, Y., \& Sannino, A. (2010). Studies of expansive learning: Foundations, findings and future challenges. Educational Research Review, 5, 1-24. doi:10.1016/j.edurev.2009.12.002

Engeström, Y., \& Sannino, A. (2012). Whatever Happened to Process Theories of Learning? Learning, Culture and Social Interaction, 1(1), 45-56. doi:10.1016/j.lcsi.2012.03.002

Eteläpelto, A., Littleton, K., Lahti, J., \& Wirtanen, S. (2005). Students' accounts of their participation in an intensive long-term learning community. International Journal of Educational Research, 43(3), 183207. doi:10.1016/j.ijer.2006.06.011

Fichtner, B. (1984). Co-ordination, co-operation and communication in the formation of theoretical concepts in instruction. In M. Hedegaard, P. Hakkarainen, \& Y. Engeström (Eds.), Learning and teaching on a scientific basis: Methodological and epistemological aspects of the activity theory of learning and teaching. Aarhus: Aarhus Universitet, Psykologisk institut.

Foot, K. (2001). Cultural-historical activity theory as practical theory: Illuminating the development of a conflict monitoring network. Communication Theory, 11(1), 56-83. doi:10.1111/j.14682885.2001.tb00233.x

Goldman, S. R. (2014). Perspectives on Learning: Methodologies for Exploring Learning Processes and Outcomes. Frontline Learning Research, 2(4), 46-55. doi:10.14786/flr.v2i4.117

Greeno, J. G. (2011). A situative perspective on cognition and learning in interaction. In T. Koschmann (Ed.), Theories of learning and studies of instructional practice (Vol. 1, pp. 41-71). New York: Springer.

Greeno, J. G., \& Engeström, Y. (2014). Learning in activity. In R. K. Sawyer (Ed.), The Cambridge handbook of the learning sciences (2nd ed., pp. 128-147). Cambridge: Cambridge University Press.

Jordan, B., \& Henderson, A. (1995). Interaction analysis: Foundations and practice. The Journal of the Learning Sciences, 4, 39-103.

Kärkkäinen, M. (1999). Teams as breakers of traditional work practices: A longitudinal study of planning and implementing curriculum units in elementary school teacher teams. Helsinki: University of Helsinki, Department of Education.

de Lange, T. (2011). Formal and non-formal digital practices: Institutionalizing transactional learning spaces in a media classroom. Learning, Media and Technology, 36(3), 251-275. doi:10.1080/17439884.2011.549827 
Lave, J., \& Wenger, E. (1991). Situated learning: Legitimate peripheral participation. Cambridge: Cambridge University Press.

Lemke, J. L. (1990). Talking science. Norwood, NJ: Ablex.

Lipponen, L., \& Kumpulainen, K. (2011). Acting as accountable authors: Creating interactional spaces for agency work in teacher education. Teaching and Teacher Education, 27(5), 812-819. doi:10.1016/j.tate.2011.01.001

Nilsson, M. (2003). Transformation through integration: An activity theoretical analysis of school development as integration of child care institutions and elementary school. Karlskrona: Blekinge Institute of Technology.

Raeithel, A. (1983). Tätigkeit, arbeit und praxis. Frankfurt am Main: Campus.

Roschelle, J., \& Teasley, S. (1995). The construction of shared knowledge in collaborative problem solving. In C. E. O'Malley (Ed.), Computer-supported collaborative learning. Heidelberg: Springer-Verlag.

Saari, E. (1995). Voidaanko tutkimusryhmiä perustaa? Tapaustutkimus Valtion teknillisen tutkimuskeskuksen metallilaboratorion ryhmäkokeilusta vuosina 1989-1991. [Could the research groups be founded? A case study of Metals Laboratory's team experimentation in 1989-1991 at the Technical Research Centre of Finland] VTT Tiedotteita 1627. Espoo: VTT Offsetpaino.

Schmittau, J., \& Morris, A. (2004). The development of algebra in the elementary mathematics curriculum of V.V. Davydov. The Mathematics Educator, 8(1), 60-87.

Seppänen, L. (2004). Learning challenges in organic vegetable farming: An activity-theoretical study of onfarm practices. Helsinki: University of Helsinki, Institute for Rural Research and Training.

Sfard, A. (1998). On two metaphors of learning and the dangers of choosing just one. Educational Researcher, 27(2), 4-13. doi:10.3102/0013189X027002004

Virkkunen, J., \& Newnham, D. S. (2013). The Change Laboratory: A tool for collaborative development of work and education. Rotterdam, the Netherlands: Sense Publishers.

Wenger, E. (1998). Communities of practice: Learning, meaning and identity. Cambridge: Cambridge University Press. 